\title{
Dolphins and diabetes: applying one health for breakthrough discoveries
}

\author{
Stephanie Venn-Watson* \\ Translational Medicine and Research Program, National Marine Mammal Foundation, San Diego, CA, USA \\ *Correspondence: stephanie.venn-watson@nmmf.org \\ Edited and reviewed by: \\ Aaron Vinik, Eastern Virginia Medical School, USA
}

Keywords: bottlenose dolphin, insulin resistance, marine mammal, metabolic syndrome, one health, type 1 diabetes, type 2 diabetes

The vigilant care of approximately 80 bottlenose dolphins (Tursiops truncatus) at the Navy Marine Mammal Program (MMP) has led to this population's higher annual survival rates, a 10year longer lifespan, and a higher proportion of dolphins living 30-50 years compared to their wild counterparts $(1,2)$. The MMP's unprecedented biobank of tens of thousands of archived clinical samples, collected as part of their care throughout the dolphins' lives for near a half-century, has been key to improving their health, as well as to discovering the unexpected. During 2007, our clinical research team was reviewing feeding and fasting blood data from thousands of clinical blood samples. Surprisingly, dolphins appeared to readily switch in and out of diabetes-like states. Overnight fasted samples collected in the morning had changes mimicking populations of people with diabetes, including increased glucose, gamma-glutamyl transpeptidase, alkaline phosphatase; and decreased uric acid compared to samples collected from the same dolphins later in the day (3). When dolphins were fed a big meal of fish, they had an insulin-resistant response (sustained postprandial hyperglycemia and hyperinsulinemia) (4). When fed water with $10 \%$ dextrose, however, they had an insulindeficient response (sustained postprandial hyperglycemia with no insulin) (5). Thus, dolphins could switch in and out of both type 2 and type 1 diabetes-like states.

These metabolic switches in dolphins were initially believed to be limited to a natural, non-pathologic state. We now know, however, that dolphins can develop metabolic syndrome, a disease also called prediabetes in humans, which affects one of every three adults in the U.S. (4-10). Interestingly, there is common ground for co-evolved metabolism in dolphins and humans, including shared large brain sizes with high demands for readily available glucose and red blood cells that rapidly transport glucose, a trait once thought to be unique to primates $(11,12)$. Further, the carnivore hypothesis proposes that insulin resistance in humans evolved to sustain adequate glucose levels when few dietary carbohydrates were available during the Ice Age (13). This evolutionary driver for insulin resistance coincides well with the movement of dolphins from land to sea and their similar dietary shift from a high carbohydrate to high protein diet (14).

This Frontiers in Endocrinology Research Topic, "Marine Mammals as Out-of-the-box Models for Diabetes and Insulin Resistance," brings together novel science and sage thoughts from multiple disciplines of experts who sought to expand our knowledge of dolphin metabolism, metabolic disease, and their relevance to human health. New science shared within includes identification of case and reference dolphin populations for metabolic syndrome, which open promising doors to discovering risk and protective factors for this disease (5). Dr. Randall Wells et al. review the life history of free-ranging dolphins living in Sarasota Bay, FL, USA to propose potential means to treat and prevent insulin resistance, including diversifying fish species eaten, and grazing or snacking throughout the day and night instead of eating fewer, large meals (15).

Dr. Benjamin Neely et al. dive deeper to assess the potential risk of insulin resistance in dolphins with lower levels of highweight adiponectin $(5,16)$. Previous studies in mice and humans have demonstrated the insulin-sensitizing effect of adiponectin and its decreasing beneficial impact in the face of iron overload. Dr. Neeley et al.'s discovery of disrupted associations between adiponectin and glucagon in dolphins with high insulin and iron overload, paired with high sequence similarity of dolphin and human adiponectin, continue to support increasing high-weight adiponectin as a potential therapeutic target for people and other animals with these diseases (16). Dr. Kirsten Eberle et al. use their newly developed, dolphin-specific immunoassays to characterize inflammation present in a 46-year old dolphin with metabolic syndrome and iron overload compared to a dolphin without these diseases (17). Parallels in chronic inflammation among people and dolphins with metabolic syndrome are reported, enhancing the emerging story of chronic inflammation and metabolic perturbations.

Dr. Thomas Schermerhorn describes how the same metabolic response can be normal in carnivores (cats and dolphins) but cause diabetes in humans, providing potential clues as to how insulin resistance may be better controlled in humans (18). A review of northern elephant seal metabolism by Dr. Dorian Houser et al. showcases an extreme version of fasting metabolism in mammals, including their amazing ability to fast for months and sustain a diabetes-like state without developing ketoacidosis (19). Understanding how northern elephant seals can protect themselves against this deadly metabolic state may lead to new approaches in humans with type 1 diabetes. Dr. Sam Ridgway demonstrates dolphins' lack of an increased respiratory quotient (i.e., oxidative response) while metabolizing glucose, a potential 
trick that may protect dolphins against the direct, damaging effects of hyperglycemia (20).

This Research Topic also has two articles proposing dolphins, with large volumes of forcefully exhaled breaths from deep lung, as ideal for discovering novel breath-based indicators of metabolism $(20,21)$. Dolphins have evolved to move large amounts of oxygen from the air into their blood with extreme efficiency using double capillary layers in the lungs. In turn, this trait enables blood-based metabolites to cross over to their breath, providing a gift of clean, compound-rich exhaled breath condensate prime for biomarker discovery. These biomarkers may one day enable noninvasive screening and monitoring of metabolic health in humans and wild cetaceans (22).

The global pandemic of diabetes demands big, game-changing discoveries. Outside traditional scientific laboratories are millions of years of trials that have led to an estimated 8.7 million eukaryotic species on Earth, most of which are in the ocean (23). Today, mechanical engineers are looking to butterflies, bees, and cheetahs for novel ideas to advance machines. Similarly, we can look increasingly to nature for new approaches to cure diseases. By doing so, there comes the benefit of calling upon human health experts to improve animal and environmental health, too. This is the core of the global One Health movement. By taking exceptional care of one together, we can help many. Earth's 8.7 million species, including the bottlenose dolphin, means 8.7 million chances to make big, positive changes, including better preventing, managing, treating, and curing diabetes. As we move forward, may we actively engage in applying One Health to work together - as physicians, veterinarians, scientists, and biologists - to improve health for all.

\section{REFERENCES}

1. Venn-Watson S, Jensen ED, Smith CR, Xitco M, Ridgway SH. Annual survival, mortality, and longevity of bottlenose dolphins (Tursiops truncatus) at the U.S. Navy Marine Mammal Program, 2004-2013. J Am Vet Med Assoc (2015).

2. Venn-Watson S, Jensen ED, Ridgway S. Population health indicators of the Navy Marine Mammal Program bottlenose dolphin (Tursiops truncatus) population, 1988-2007. JAm Vet Med Assoc (2011) 238:356-60. doi:10.2460/javma.238.3.356

3. Venn-Watson S, Ridgway SH. Big brains and blood glucose: common ground for diabetes mellitus in humans and healthy dolphins. Comp Med (2007) 57(4):390-5.

4. Venn-Watson S, Carlin K, Ridgway S. Dolphins as animal models for type 2 diabetes: sustained, postprandial hyperglycemia and hyperinsulinemia. Gen Comp Endocrinol (2011) 170:193-9. doi:10.1016/j.ygcen.2010.10.005

5. Venn-Watson S, Smith CR, Stevenson S, Parry C, Daniels R, Jensen E, et al. Blood-based indicators of insulin resistance and metabolic syndrome in bottlenose dolphins (Tursiops truncatus). Front Endocrinol (2013) 4:136. doi:10. 3389/fendo.2013.00136

6. Venn-Watson S, Benham C, Carlin K, St Leger J. Hemochromatosis and fatty change: building evidence for insulin resistance in bottlenose dolphins (Tursiops truncatus). J Zoo Wildl Med (2012) 43:S35-47. doi:10.1638/2011-0146.1

7. Mazzaro LM, Johnson SP, Fair PA, Bossart G, Carlin KP, Jensen ED, et al. Iron indices among bottlenose dolphins (Tursiops truncatus): identifying populations at risk for iron overload. Comp Med (2012) 62:508-15.

8. Venn-Watson S, Townsend FI, Daniels R, Sweeney J, McBain J, Klatsky L, et al. Hypocitraturia in Atlantic bottlenose dolphins (Tursiops truncatus): assessing a potential risk factor for urate nephrolithiasis. Comp Med (2010) 60:149-53.
9. Venn-Watson S, Smith CR, Gomez F, Jensen ED. Physiology of aging among healthy, older bottlenose dolphins (Tursiops truncatus): comparisons with aging humans. J Comp Physiol B (2011) 181:667-80. doi:10.1007/s00360-011-0549-3

10. Centers for Disease Control and Prevention. National Diabetes Statistics Report: Estimates of Diabetes and Its Burden in the United States. Atlanta, GA: U.S. Department of Health and Human Service (2014). Available from: http://www.cdc.gov/ diabetes/pubs/statsreport14/national-diabetes-report-web.pdf (2014)

11. Marino L. A comparison of encephalization between odontocete cetaceans and anthropoid primates. Brain Behav Evol (1998) 51:230-8. doi:10.1159/000006540

12. Craik JD, Young JD, Chesseman CI. GLUT-1 mediation of rapid glucose transport in dolphin (Tursiops truncatus) red blood cells. Am J Physiol (1998) 274:R112-9.

13. Miller JCB, Colagiuri S. The carnivore connection: dietary carbohydrate in the evolution of NIDDM. Diabetologia (1994) 37:1280-6. doi:10.1007/BF00399803

14. Thewissen JGM, Madar SI. Ankle morphology of the earliest cetaceans and its implications for the phylogenetic relations among ungulates. Syst Biol (1999) 48:21-30. doi:10.1080/106351599260418

15. Wells RS, McHugh KA, Douglas DC, Shippee S, McCabe EB, Barros NB, et al. Evaluation of potential protective factors against metabolic syndrome in bottlenose dolphins: feeding and activity patterns of dolphins in Sarasota Bay, Florida. Front Endocrinol (2013) 4:139. doi:10.3389/fendo.2013.00139

16. Neely BA, Carlin KP, Arthur JM, McFee WE, Janech MG. Ratiometric measurements of adiponectin by mass spectrometry in bottlenose dolphins (Tursiops truncatus) with iron overload reveal an association with insulin resistance and glucagon. Front Endocrinol (2013) 4:132. doi:10.3389/fendo.2013.00132

17. Eberle KC, Waters TE, Jensen ED, Venn-Watson SK, Sacco RE. Development and application of specific cytokine assays in tissue samples from a bottlenose dolphin with hyperinsulinemia. Front Endocrinol (2013) 4:134. doi:10.3389/fendo.2013.00134

18. Schermerhorn T. Normal glucose metabolism in carnivores overlaps with diabetes pathology in non-carnivores. Front Endocrinol (2013) 4:188. doi:10.3389/ fendo.2013.00188

19. Houser DS, Champagne CD, Crocker DE. A non-traditional model of the metabolic syndrome: the adaptive significance of insulin resistance in fasting-adapted seals. Front Endocrinol (2013) 4:164. doi:10.3389/fendo.2013.00164

20. Ridgway SH. A mini review of dolphin carbohydrate metabolism and suggestions for future research using exhaled air. Front Endocrinol (2013) 4:152. doi:10.3389/fendo.2013.00152

21. Schivo M, Aksenov AA, Yeates LC, Pasamontes A, Davis CE. Diabetes and the metabolic syndrome: possibilities of a new breath test in a dolphin model. Front Endocrinol (2013) 4:163. doi:10.3389/fendo.2013.00163

22. Akseov AA, Yeates L, Pasamontes A, Siebe C, Zrodnikov Y, Simmons J, et al. Metabolite compound profiling of bottlenose dolphin exhaled breath. Anal Chem (2014) 86:10616-24. doi:10.1021/ac5024217

23. Mora C, Tittensor DP, Adl S, Simpson AGB, Worm G. How many species are there on Earth and in the Ocean? PLoS Biol (2011) 9:e1001127. doi:10.1371/ journal.pbio. 1001127

Conflict of Interest Statement: The author declares that the research was conducted in the absence of any commercial or financial relationships that could be construed as a potential conflict of interest.

Received: 18 June 2014; accepted: 09 December 2014; published online: 22 December 2014.

Citation: Venn-Watson S (2014) Dolphins and diabetes: applying one health for breakthrough discoveries. Front. Endocrinol. 5:227. doi: 10.3389/fendo.2014.00227

This article was submitted to Diabetes, a section of the journal Frontiers in Endocrinology.

Copyright (C) 2014 Venn-Watson. This is an open-access article distributed under the terms of the Creative Commons Attribution License (CC BY). The use, distribution or reproduction in other forums is permitted, provided the original author(s) or licensor are credited and that the original publication in this journal is cited, in accordance with accepted academic practice. No use, distribution or reproduction is permitted which does not comply with these terms. 